\title{
NEW LIGHTWEIGHT DESIGN FOCUS: THE COCKPIT BEAM
}

\author{
The lightweight solutions presented back in 2009 are being further developed by ThyssenKrupp as part of \\ the InCar plus project. In addition, the second project from 2014 is also offering new solution approaches, \\ e.g. a cockpit beam which is around $3.4 \mathrm{~kg}$ lighter than current steel solutions. With lightweight design costs \\ of $€ 5.30 / \mathrm{kg}$, it offers easily accessible potential for saving weight.
}

While updating the InCar plus reference structure, the body and near-body components such as closures and add-on parts were investigated as regards their potential weight savings. One component in which lightweight measures are especially worthwhile is the cockpit beam. To obtain an overview of the trends and products in this field, the ThyssenKrupp engineers compared almost 300 different cockpit beams. Important parameters include the use of material, the connection and support points, and weights. Steel is the preferred material in $64 \%$ of the investigated cockpit beams, followed by diecast magnesium and aluminum. The average weight of the investigated cockpit beams is $7.5 \mathrm{~kg}$ (steel), $4.5 \mathrm{~kg}$ (aluminum) and $3.5 \mathrm{~kg}$ (magnesium).
To reveal the weight advantages of magnesium sheet, ThyssenKrupp developed an alternative concept using flat magnesium products. This new cockpit beam consists of a twin-tube system with additional magnesium sheet components and is joined by means of MAG welding,

The cockpit beam's usage characteristics are validated virtually. For the simulations, a widely used steering column and a substitute mass for the steering wheel are added to the cockpit beam. Integration into a rigid frame guarantees a manufacturer-neutral installation situation. Global natural frequencies include the lateral mode with $42.0 \mathrm{~Hz}$ and the vertical mode with $45.0 \mathrm{~Hz}$. The high natural frequencies reflect the cockpit beam's good stiffness-to-weight ratio. At
$3 \mathrm{~Hz}$, it is additionally guaranteed that the spread between the first global modes is sufficiently large. As further verification of the usage characteristics, a vertical load of $100 \mathrm{~kg}$ is applied onto the steering wheel. At $95 \mathrm{MPa}$, the stresses induced in the cockpit beam are around $44 \%$ less than the yield stress of Mg AZ31. This therefore guarantees that no plastic deformation will occur during daily use.

The magnesium sheet cockpit beam developed in the InCar plus project weighs $2.4 \mathrm{~kg}$. If this is compared with an optimized steel cockpit beam weighing $5.8 \mathrm{~kg}$, the lightweight design costs amount to $€ 5.30 / \mathrm{kg}$. Magnesium sheet components therefore offer great potential for reducing weight in vehicles.

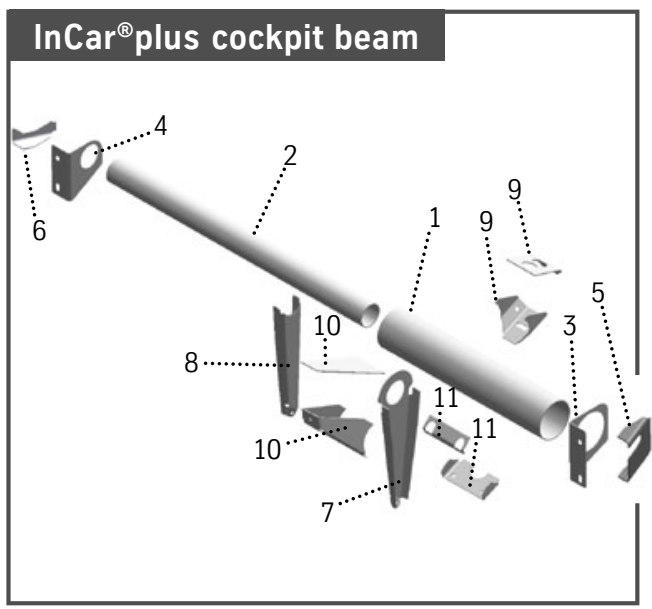

\begin{tabular}{|c|c|c|c|}
\hline No & Part & Material & Thickness \\
\hline 1 & Cross member left & AZ 31 & $2.30 \mathrm{~mm}$ \\
\hline 2 & Cross member right & AZ 31 & $1.00 \mathrm{~mm}$ \\
\hline 3 & Bracket cross member left & AZ 31 & $2.50 \mathrm{~mm}$ \\
\hline 4 & Bracket cross member right & AZ 31 & $1.00 \mathrm{~mm}$ \\
\hline 5 & Reinforcement bracket cross member left & AZ 31 & $2.50 \mathrm{~mm}$ \\
\hline 6 & Reinforcement bracket cross member left & AZ 31 & $1.00 \mathrm{~mm}$ \\
\hline 7 & Tunnel support left & AZ 31 & $1.30 \mathrm{~mm}$ \\
\hline 8 & Tunnel support right & AZ 31 & $1.00 \mathrm{~mm}$ \\
\hline 9 & Brackets steering column & AZ 31 & $2.50 \mathrm{~mm}$ \\
\hline 10 & Firewall supports & AZ 31 & $2.50 \mathrm{~mm}$ \\
\hline 11 & Brackets steering column front & AZ 31 & $2.50 \mathrm{~mm}$ \\
\hline
\end{tabular}

Magnesium sheet cockpit beam 